\title{
Comparison of Treatment Methods in Lumbar Spinal Stenosis for Geriatric Patient: Nerve Block Versus Radiofrequency Neurotomy Versus Spinal Surgery
}

\author{
Chang Kyu Park, Sung Bum Kim, Min Ki Kim, Bong Jin Park, Seok Geun Choi, \\ Young Jin Lim, Tae Sung Kim \\ Department of Neurosurgery, Kyung Hee University College of Medicine, Seoul, Korea
}

\begin{abstract}
Objective: The incidence of spinal treatment, including nerve block, radiofrequency neurotomy, instrumented fusions, is increasing, and progressively involves patients of age 65 and older. Treatment of the geriatric patients is often a difficult challenge for the spine surgeon. General health, sociofamilial and mental condition of the patients as well as the treatment techniques and postoperative management are to be accurately evaluated and planned. We tried to compare three treatment methods of spinal stenosis for geriatric patient in single institution.

Methods: The cases of treatment methods in spinal stenosis over than 65 years old were analyzed. The numbers of patients were 371 underwent nerve block, radiofrequency neurotomy, instrumented fusions from January 2009 to December 2012 (nerve block: 253, radiofrequency neurotomy: 56, instrumented fusions: 62). The authors reviewed medical records, operative findings and postoperative clinical results, retrospectively. Simple X-ray were evaluated and clinical outcome was measured by Odom's criteria at 1 month after procedures.

Results: We were observed excellent and good results in $162(64 \%)$ patients with nerve block, $40(71 \%)$ patient with radlofrequency neurotomy, $46(74 \%)$ patient with spinal surgery. Poor results were $20(8 \%)$ patients in nerve block, $2(3 \%)$ patients in radiofrequency neurotomy, $3(5 \%)$ patient in spinal surgery.

Conclusion: We reviewed literatures and analyzed three treatment methods of spinal stenosis for geriatric patients. Although the long term outcome of surgical treatment was most favorable, radiofrequency neurotomy and nerve block can be considered for the secondary management of elderly lumbar spinals stenosis patients.
\end{abstract}

Key Words: Nerve block $\cdot$ Radiofrequency neurotomy $\cdot$ Spinal surgery $\cdot$ Spinal stenosis $\cdot$ Elderly patient

\section{INTRODUCTION}

As development of medical techniques provided the extension of human life, the number of elderly has been increasing. For this reason, prevalence rate of geriatric illness is also increase with growth of needs of geriatric patients. Among numerous geriatric diseases, low back pain occupied a large proportions and their will for treatment has been changing from

- Received: July 16, 2014 - Revised: August 15, 2014

- Accepted: August 26, 2014

Corresponding Author: Sung Bum Kim, MD, PhD

Department of Neurosurgery, Kyung Hee University School of Medicine,

1 Hoegi-dong, Dongdaemun-gu, Seoul 130-702, Korea

Tel: +82-2-958-8402, Fax: +82-2-958-8380

E-mail: sungbumi7@ hanmail.net

$\otimes T h i s$ is an Open Access article distributed under the terms of the Creative

Commons Attribution Non-Commercial License (http://creativecommons.org/ licenses/by-nc/3.0/) which permits unrestricted non-commercial use, distribution, and reproduction in any medium, provided the original work is properly cited. conservative medical treatment to aggressive surgical treatment. Because many factors were involved in low back pain, it is hard to make a appropriate decision for treatment of low back pain in old patinets.

Among many factors causing low back pain, degenerative lumbar spinal stenosis is a major cause of pain in people over the age of 65 years $^{16}$. Nonsurgical managements for treatment of spinal stenosis have been known as nonsteroidal anti-inflammatory drugs, physical therapy, and local nerve block, etc. Surgical treatment is indicated when nonsurgical management is unsuccessful and neurologic decline persists or progresses ${ }^{8)}$. However, surgical treatment for elderly people is believed to be more difficult than younger people because of the systemic changes associated with aging. Although the evidence from current literatures suggests that surgical intervention is effective, the recent studies report that patients treated non-operatively also showed improved results ${ }^{13,15)}$. Thus non-operative treatment such as nerve block, radiofrequency neurotomy often performed to elderly patient recently. 
In present study, we analyzed and compared clinical outcome and efficacy of treatment to elderly patients who underwent nerve block, radiofrequency neurotomy and surgery for spinal stenosis in our hospital.

\section{MATERIALS AND METHODS}

\section{Subjects}

Case of 371 patients who over the age of 65 years and underwent nerve block, radiofrequency neurotomy or surgery for spinal stenosis at our center between January 2009 and December 2012 were retrospectively analyzed. We reviewed medical and surgical record, radiological study such as magnetic resonance image.

\section{Evaluation of Lumbar Spinal Stenosis}

Most patients underwent MR imaging of the lumbar spine at our clinic or others, and the extent of spinal stenosis could be estimated. Compression of the lumbar dural sac was clearly delineated. We also routinely performed plain anteroposterior and lateral radiography of the lumbar spine to exclude developmental disorders. Additionally, we divided to spinal stenosis severity as defined by Schonstrom ${ }^{20)}$. It is using dural sac cross-sectional area (DSCA) measurement on magnetic resonance imaging studies. A DSCA of $<100 \mathrm{~mm}^{2}$ has been suggested to represent mild stenosis, a DSCA of $75-100 \mathrm{~mm}^{2}$ has been suggested to represent moderate stenosis, while a DSCA of $<75 \mathrm{~mm}^{2}$ gives a severe stenosis. And we were researching mild and moderate stenosis groups.

\section{Indications for Treatment}

\section{1) Nerve Block}

Before treatment, the patient received medical therapy to manage their pain, minimally consisting of physical therapy and the use of NSAIDs if not contraindicated. In case of insufficient pain relief, patients were judged eligible for nerve block treatment.

\section{2) Radiofrequency Neurotomy}

Among the patients received nerve block, when nerve block performed if there is a $50 \%$ reduction in symptoms after the intervention, the patients were judged suitable for radiofrequency neurotomy.

\section{3) Surgery}

We performed the surgery when the following criteria were met: there were clear symptoms of neural claudication with corresponding signs of a radiological correlate, 3 months of conservative treatment, which included nerve block and radiofrequency neurotomy, did not improve the patient's symptoms. We selected patients who underwent only posterolateral interbody fusion except other surgery for direct comparison of clinical outcome.

\section{Procedures of Treatment}

\section{1) Nerve Block}

All injection procedures were performed under fluoroscopic guidance while the patient was lying in prone position. Also injection were performed using established techniques using lidocaine $(0.5 \%)$ and methylprednisolone.

\section{2) Radiofrequency Neurotomy}

A radiofrequency neurotomy was only considered after positive testing (at leat 50\% pain relief). Procedures were performed with fluoroscopic visualization. The level of spinal stenosis was always included in the radiofrequency neurotomy. In nearly all patients, one or 2 adjacent levels were also included. For radiofrequency neurotomy a NeuroTherm NT 1,000 generator was used. The cannulae used were $150 \mathrm{~mm}$ length, 20-gauge with a $10 \mathrm{~mm}$ active tip. The total time of the lesion at $42^{\circ} \mathrm{C}$ was 120 seconds for each cycle at each level. At each level, the needle was placed parallel to the nerve; multiple lesions were made in parallel for each medial branch. Lidocaine was used as a local anaesthetic. Sometimes, nerve stimulation was performed prior to radiofrequency lesioning.

\section{3) Spinal Surgery}

Almost patients received posterolateral interboby fusion and posterior screw fixation. Surgery was performed using established techniques in one level which include spinal stenosis lesion.

\section{Evaluations of Clinical Outcome}

Clinical outcome was determined according to scoring and changes on the visual analogue scale (VAS) for pain and Odom's criteria at the time of pre-procedures and at 1 month after 
procedures. Additionally, the changes of lumbar spine were assessed with a lumbar spine plain radiography.

\section{RESULTS}

\section{Patient Characteristics}

Among 371 patients who over the age of 65 years and underwent treatments for spinal stenosis at our center between January 2009 and December 2012, nerve block was performed in 253 patients, radiofrequency neurotomy was performed in 56 patients and surgery was performed in 62 patients. These represent about $68.2 \%, 15.1 \%, 16.7 \%$ of all patient undergoing treatment for spinal stenosis, respectively. The mean age of the patients who underwent nerve block was $70.6 \pm 4.5$ years (mean \pm SD, range: $65-87$ ), among whom 80 were males and 173 were females. The mean age of the patients who underwent radiofrequency neurotomy was $72.2 \pm 1.9$ years (mean \pm SD, range: 65-75), among whom 19 were males and 37 were females. The mean age of the patients who underwent surgery was 69.4 \pm 6.0 years (mean $\pm \mathrm{SD}$, range: $65-80$ ), among whom 28 were males and 34 were females (Table 1).

\section{Clinical Manifestations by Treatments}

These are summarized in Table 2.

\section{1) Nerve Block}

Among 253 patients, 114 patients did complain of a low back pain, 113 patients did complain of a radiculopathy and the remaining 26 patients did complain of a neurogenic claudiacation.

Table 1. Demographics of patients

\begin{tabular}{lccc}
\hline & Nerve Block & RF & Surgery \\
\hline Number of Patients & 253 & 56 & 62 \\
Age, years, mean \pm SD & $70.6 \pm 4.5$ & $72.2 \pm 1.9$ & $69.4 \pm 6.0$ \\
Sex, n (M:F) & $80: 173$ & $19: 37$ & $28: 34$ \\
\hline "RF: Radiofrequency neurotomy & &
\end{tabular}

Table 2. Clinical manifestation of each treatment

\begin{tabular}{lccc}
\hline \hline & Nerve Block & RF & Surgery \\
\hline Claudication & $26(10 \%)$ & $3(5 \%)$ & $16(26 \%)$ \\
Radicular Pain & $113(45 \%)$ & $41(73 \%)$ & $32(52 \%)$ \\
Back pain & $114(45 \%)$ & $12(22 \%)$ & $14(22 \%)$ \\
\hline
\end{tabular}

*RF: Radiofrequency neurotomy

\section{2) Radiofrequency Neurotomy}

Among 56 patients, 41 patients did complain of a radiculopathy, 12 patients did complain of a low back pain and the remaining 3 patients did complain of a neurogenic claudiacation.

\section{3) Surgery}

Among 62 patients, 32 patients did complain of a radiculopathy, 16 patients did complain of a neurogenic claudication and the remaining 14 patients did complain of a low back pain.

\section{Clinical Outcomes}

\section{1) By VAS for Pain}

In cases of nerve block, the mean score of pre-nerve block was $6.9 \pm 1.2$, and then the mean score was $3.7 \pm 1.4$ at 1 month after procedure. In cases of radiofrequency neurotomy, the mean score of pre-radiofrequency neurotomy was $7.4 \pm 0.6$, and then the mean score was $3.4 \pm 0.8$ at 1 month later. In cases of surgery, the mean score of pre-surgery was $7.5 \pm 0.5$, the mean score of a month after post-surgery was $3.4 \pm 0.4$ (Table 3).

\section{2) By Odom's Criteria}

At 1 month after treatment, review of the post-treatment of patient who underwent nerve block revealed 163 patients (64\%) with excellent or good and 20 patients (8\%) with poor grade. In cases of radiofrequency neurotomy, 40 patients (71\%) represented excellent or good and 2 patients (3\%) represented poor. Out of 62 patients who underwent surgery, 46 patients (74\%) expressed excellent or good and 3 patients (5\%) expressed poor (Table 4).

\section{3) Retreatments and Complication}

Among the nerve block group, 101 patients received retreatment because insufficient pain relief and complication of infection occurred in 1 patient. In cases of radiofrequency

Table 3. Clinical results: VAS

\begin{tabular}{lcc}
\hline \hline & Pre-treatment & 1 month later \\
\hline Nerve Block & $6.9 \pm 1.2$ & $3.7 \pm 1.4$ \\
RF & $7.4 \pm 0.6$ & $3.4 \pm 0.8$ \\
Surgery & $7.5 \pm 0.5$ & $3.4 \pm 0.4$ \\
\hline
\end{tabular}

"RF: Radiofrequency neurotomy 
Table 4. Clinical outcomes: Odom's criteria

\begin{tabular}{lccc}
\hline & Nerve Block & RF & OP \\
\hline Excellent or Good & $162(64 \%)$ & $40(71 \%)$ & $46(74 \%)$ \\
Poor & $20(8 \%)$ & $2(3 \%)$ & $3(5 \%)$ \\
Retreatment & $101(40 \%)$ & $3(5 \%)$ & $2(3 \%)$ \\
\hline${ }^{*}$ RF: Radiofrequency neurotomy & &
\end{tabular}

neurotomy, 3 patients received retreatment and there were no complications. Among surgical group, 2 patients received revision surgery and 2 cases of complications occurred it was post-operative infections.

\section{DISCUSSION}

Spinal stenosis is a degenerative condition that affects the lumbar spine. This can be an incidental finding, but can cause back and leg symptoms, or neurogenic claudication ${ }^{11)}$. The prevalence of symptomatic spinal stenosis is likely to increase with growing cohorts of the old and very old ${ }^{17}$. Stenosis in the lumbar spine is considered to have both structural and dynamic components, as walking causes further narrowing of the spinal canals and an increase in epidural pressure ${ }^{2)}$. Patients are typically aged over 50 years with a long history of back pain, extensive degenerative changes on radiography and neurological deficits in some patients ${ }^{14)}$.

Surgery for spinal stenosis has been on the increase. Some good outcomes from surgical interventions have been demonstrated, but outcomes vary widely, and complications and re-operations have been reported ${ }^{15,19)}$. The natural history of spinal stenosis and response to non-surgical care can be favorable with numerous therapies being proposed ${ }^{2}$. So our study analyzed and compared clinical outcome and efficacy of treatment to elderly patients who underwent nerve block, radiofrequency neurotomy and surgery for spinal stenosis in our hospital.

The scientifically valid studies that have been performed in this area to date are few, and none of them had a clear age limit or age restriction. Direct comparisons of conservative and surgical treatment are further complicated by the fact that patients with mild stenosis generally undergo the former, while those with severe stenosis generally undergo the latter. Chou et al., in a review of this topic, concluded that moderately good evidence indicates the superiority of surgical over conservative treatment in the first two years. The available evidence is hard to assess, however, because the six randomized trials whose findings were presented involved different surgical methods and variable follow-up intervals ${ }^{6}$.

Atlas et al. prospectively followed patients for eight to ten years and found better results in the first four years in the patients who had undergone surgery. At the end of the follow-up period, however, the two groups no longer differed with respect to low back pain or overall satisfaction, while all patients had a marked reduction of the leg-pain component. It must be noted, however, that $37 \%$ of the patients who were initially treated conservatively went on to have surgery. Radicular symptoms were improved in $67 \%$ of the patients who had surgery and in $41 \%$ of those treated conservatively ${ }^{4}$. Chang et al., too, found that surgery yielded better results than conservative treatment after ten years of follow-up ${ }^{5)}$. Analogously to the observations of Atlas et al., the two groups no longer differed with respect to low back pain or overall satisfaction, while the surgical patients had greater improvements in functional status and leg pain. In addition, Jang et al. reported that decompressive laminectomy alone is a relatively safe and effective treatment option for the elderly ${ }^{7}$. In our study, similarly, VAS score of surgery group was decreased 1 month after surgery and $74 \%$ of surgery group had excellent or good outcome.

Lumbar spinal stenosis is being treated surgically with more frequency. However, clinical experience indicates that many patients also do well on a regimen conservative treatment only. And it can be performed more frequently in elderly patients.

In 2011, Boxem et al. reported that among the patient who underwent radiofrequency neurotomy for spinal stenosis, $22.9 \%$ presented $50 \%$ pain relief after 6 months and after 12 months in $13.1 \%$ of the cases ${ }^{22)}$. Similarly, in 2012, Klessinger reported that during a time period of 3 years, 1490 patients were treated with lumbar radiofrequency neurotomy. A significant pain reduction was achieved in $65 \%$ of the patients ${ }^{12}$. Roy et al. reported that a patient had a mean VAS score of 8.6 before the radiofrequency neurotomy and steroid block. Thereafter, VAS score was 0.91 immediately after the procedure and 0.3, 2.8, 3.7 and 3.6 at 1 month, 2 months, 6 months, and 1 year $^{18)}$. In our study, both nerve block and radiofrequency neurotomy had favorable outcome. Especially, radiofrequency neurotomy group had a mean VAS score of 7.4 before the treatment. And the mean score of immediately post-radiofrequency neurotomy was 3.4 and then the mean score of recent follow up was 1.3. And our study indicated that $71 \%$ of the radiofrequency neurotomy group presented excellent or good outcome by pain reduction after radiofrequency nuerotomy.

The complication rate after surgical treatment of spinal stenosis is considerable. In a prospective study published in 2010, 101 patients over the age of 70 who underwent surgery had an $18 \%$ complication rate. The most common complication was a dural injury without further clinical consequences (9\%). Two patients had deep wound infections, and three died of 
concomitant, unrelated illnesses 26 days, 9 months, and 11 months after surgery". In our study, among surgical group, 4 cases $(6 \%)$ of complications occurred it was post-operative infections ( 2 cases) and adjacent segment disease ( 2 cases). On the other hand, no complications of radiofrequency neurotomy were reported, also in the other studies, there was no mention of neurological complications. Furthermore, inadequate decompression may leave a significant degree of recurrent stenosis. Jansson et al. documented a reoperation rate of $11 \%$ over ten years of follow up ${ }^{10)}$. In our study, 2 patients received revision surgery. However, if we have a long term follow up for surgery group, we may observe other complication such as adjacent segment disease. Adjacent segment disease is complication following spinal fusion. This is a broad term that encompasses symptoms such as listhesis, instability, herniated nucleus pulposus, stenosis, hypertrophic facet arthritis, scoliosis, and vertebral compression fracture.

The pain relief from the radiofrequency neurotomy is sufficient to allow many of the patients to improve their activity tolerance and reduce other therapies for pain ${ }^{1,12,18)}$. And there is no contraindication to repeating the denervation if the symptoms recur, nor is there an additional technical disadvantage presented by repeat denervation. Compared with surgical therapy, these considerations favor the minimally invasive route in elderly patient.

A limitations of our study; first, it was selection of patient groups. We studied to only mild to moderate stenosis patients, excluding severe stenosis patient who need to surgical treatment. Also, in our study, we performed nerve block or radiofrequency neurotomy to patients who do not need to surgery. Therefore, our results were barely suitable for comparison to surgical outcomes. Second, we did not long term follow up. Slatis et al. reported that, based on data concerning functional ability and perceived back and leg pain, surgical treatment of lumbar spinal stenosis provided better results than conservative methods of treatment at the 6-year follow up ${ }^{211}$. And Amundsen et al., too, concluded that the outcome was most favorable for surgical treatment in their 10-year prospective study ${ }^{3}$. Lumbar spinal stenosis worsen as time go on because it is degenerative disease. Therefore, we evaluate clinical outcome at 1 month after procedure to assess effectiveness of treatment in the short term.

According to the above mentioned, long term outcomes of surgical treatment were better than conservative manage such as nerve block and radiofrequency neurotomy. However, we suggest that radiofrequency neurotomy may consider the effective secondary treatment to elderly patient that unable or refuse to surgery for lumbar spinal stenosis.

\section{CONCLUSION}

Recently, many of therapies were development and performed for symptomatic spinal stenosis because the symptoms related to quality of life in elderly patients. In our study, as a result of effectiveness of treatment for spinal stenosis, we found that radiofrequency neurotomy and nerve block were effective treatment. Although the long term outcome of surgical treatment was most favorable, radiofrequency neurotomy and nerve block can be considered for the secondary management of elderly lumbar spinals stenosis patients.

\section{REFERENCES}

1. Abejon D, Ortego R, Solis R, Alaoui N, del Saz J, del Pozo $\mathrm{C}$ : Trans-facet-joint approach to pulsed radiofrequency ablation of the 15 dorsal root ganglion in a patient with degenerative spondylosis and scoliosis. Pain Pract 8(3):202-205, 2008

2. Ammendolia C, Stuber KJ, Rok E, Rampersaud R, Kennedy CA, Pennick V, et al: Nonoperative treatment for lumbar spinal stenosis with neurogenic claudication. Cochrane Database Syst Rev 8:CD010712, 2013

3. Amundsen T, Weber H, Nordal HJ, Magnaes B, Abdelnoor M, Lilleas F: Lumbar spinal stenosis: Conservative or surgical management?: A prospective 10-year study. Spine (Phila $\mathrm{Pa} 1976$ ) 25(11):1424-1435; discussion 1435-1426, 2000

4. Atlas SJ, Keller RB, Wu YA, Deyo RA, Singer DE: Long-term outcomes of surgical and nonsurgical management of lumbar spinal stenosis: 8 to 10 year results from the maine lumbar spine study. Spine (Phila Pa 1976) 30(8):936-943, 2005

5. Chang Y, Singer DE, Wu YA, Keller RB, Atlas SJ: The effect of surgical and nonsurgical treatment on longitudinal outcomes of lumbar spinal stenosis over 10 years. J Am Geriatr Soc 53(5): 785-792, 2005

6. Chou R, Baisden J, Carragee EJ, Resnick DK, Shaffer WO, Loeser JD: Surgery for low back pain: A review of the evidence for an american pain society clinical practice guideline. Spine (Phila Pa 1976) 34(10):1094-1109, 2009

7. Il-Tae Jang, Sang-Won Lee, Paul M. Atienza, Jang-Seon You: Decompressive surgery alone for lumbar spinal stenosis in elderly patients. Korean J Spine 5:83-88, 2008

8. Issack PS, Cunningham ME, Pumberger M, Hughes AP, Cammisa FP, Jr.: Degenerative lumbar spinal stenosis: Evaluation and management. J Am Acad Orthop Surg 20(8):527-535, 2012

9. Jakola AS, Sorlie A, Gulati S, Nygaard OP, Lydersen S, Solberg $\mathrm{T}$ : Clinical outcomes and safety assessment in elderly patients undergoing decompressive laminectomy for lumbar spinal stenosis: A prospective study. BMC Surg 10:34, 2010

10. Jansson KA, Nemeth G, Granath F, Blomqvist P: Spinal stenosis re-operation rate in sweden is $11 \%$ at 10 years--a national analysis of 9,664 operations. Eur Spine J 14(7):659-663, 2005

11. Kalff R, Ewald C, Waschke A, Gobisch L, Hopf C: Degenerative 
lumbar spinal stenosis in older people: Current treatment options. Dtsch Arztebl Int 110(37):613-623, 2013

12. Klessinger S: Radiofrequency neurotomy for treatment of low back pain in patients with minor degenerative spondylolisthesis. Pain Physician 15(1):E71-78, 2012

13. Kovacs FM, Urrutia G, Alarcon JD: Surgery versus conservative treatment for symptomatic lumbar spinal stenosis: A systematic review of randomized controlled trials. Spine (Phila Pa 1976) 36(20):E1335-1351, 2011

14. Kurd MF, Lurie JD, Zhao W, Tosteson T, Hilibrand AS, Rihn $\mathrm{J}$, et al: Predictors of treatment choice in lumbar spinal stenosis: A spine patient outcomes research trial study. Spine (Phila Pa 1976) 37(19):1702-1707, 2012

15. May S, Comer C: Is surgery more effective than non-surgical treatment for spinal stenosis, and which non-surgical treatment is more effective? A systematic review. Physiotherapy 99(1):1220, 2013

16. Nanjo Y, Nagashima H, Dokai T, Hamamoto Y, Hashiguchi $\mathrm{H}$, Ishii $\mathrm{H}$, et al: Clinical features and surgical outcomes of lumbar spinal stenosis in patients aged 80 years or older: A multicenter retrospective study. Arch Orthop Trauma Surg 133(9): 1243-1248, 2013

17. Rainville J, Lopez E: Comparison of radicular symptoms caused by lumbar disc herniation and lumbar spinal stenosis in the elderly. Spine (Phila Pa 1976) 38(15):1282-1287, 2013

18. Roy C, Chatterjee N, Ganguly S, Sengupta R: Efficacy of combined treatment with medial branch radiofrequency neurotomy and steroid block in lumbar facet joint arthropathy. J Vasc Interv Radiol 23(12):1659-1664, 2012

19. Schneider M, Ammendolia C, Murphy D, Glick R, Piva S, Hile $\mathrm{E}$, et al: Comparison of non-surgical treatment methods for patients with lumbar spinal stenosis: Protocol for a randomized controlled trial. Chiropr Man Therap 22:19, 2014

20. Schonstrom N, Bolender NF, Spengler DM, Hansson TH: Pressure changes within the cauda equina following constriction of the dural sac. An in vitro experimental study. Spine (Phila Pa 1976) 9(6):604-607, 1984

21. Slatis P, Malmivaara A, Heliovaara M, Sainio P, Herno A, Kankare J, et al: Long-term results of surgery for lumbar spinal stenosis: A randomised controlled trial. Eur Spine J 20(7):11741181, 2011

22. Van Boxem K, van Bilsen J, de Meij N, Herrler A, Kessels F, Van Zundert J, et al: Pulsed radiofrequency treatment adjacent to the lumbar dorsal root ganglion for the management of lumbosacral radicular syndrome: A clinical audit. Pain Med 12(9):13221330, 2011 